\title{
IMUNOGENICIDADE DA CEPA AVIRULENTA RV194-2 DO VÍRUS RÁBICO EM CAMUNDONGOS
}

\author{
Rugimar Marcovistz, Eduardo Chaves Leal, Denise Cristina S. de Matos, \\ Humberto Pinheiro de Araújo e Henri Tsiang
}

\begin{abstract}
O vírus rábico RV194́-2, uma tariante avinulenta da cepa CVS (Challenge Virus Standard), produz uma infecção inaparente quando inoculado intracerebralmente em camundongos adultos. Sugerindo que a resposta imunológica do bospedeiro permite a eliminação do vírus do sistema nenoso central. Por esta razão foram estudadas a induçâo de interferon e a resposta imune bumoral em camundongos BALB/c inoculados com virus RV194-2. Durante a infecçäo, estes camundongos apresentaram elevados niveis de interferon no plasma e no cérebro com altos títulos de anticorpos neutralizantes anti-rábicos. A 2-5A sintetase, um marcador da ação dos interferons, foi também analisada no cérebro destes animais. Sua atividade, aumentou, paralelamente, à produção de interferon, demonstrando que este interferon é bioquimicamente ativo. O tîus RV194-2 também induziu, 45 dias após sua inoculação, proteção aos animais quando desafiados com a cepa virulenta CVS. Estes resuliados demonstram que a cepa RV194-2 possui um alto nivel imunogênico.
\end{abstract}

Palawras-chaves: Virus rábico. Interferon. Imunogenicidade.

Durante muito tempo, com base em testes imunológicos convencionais, todas as cepas de vírus rábico eram consideradas antigênicamente semelhantes ${ }^{25}$. Contudo, diferenças antigênicas entre as cepas de vírus fixo e as cepas de vírus de rua ou selvagem foram facilmente detectadas, utilizando anticorpos monoclonais contra a glicoproteína do vírus rábico ${ }^{10} 26$.

O emprego destes anticorpos monoclonais antiglicoproteína possibilitou a seleção in vitro, de cepas avirulentas variantes do vírus fixo $\mathrm{CVS}^{+8}$. Dentre estas cepas variantes avirulentas, uma demonstrou ser incapaz de reagir com dois anticorpos monoclonais antiglicoproteína do CVS (anticorpos no 248-8 e 194-2), sendo então, denominada de RV194-2. Sua avirulência foi caracterizada pela ausência de mortalidade de camundongos Suíços, quando inoculados por via intracerebral.

Dietzschold e col${ }^{8}$ estudando a molécula da glicoproteína do vírus RV194-2 observou que a

\footnotetext{
Departamento de Imunologia, Instituto Oswaldo Cruz, Fundação Oswaldo Cruz, Rio de Janeiro, Brasil Service Rage, Institut Pasteur, Paris, França.

Financiado pelo CNPq c Commission of European (contrato no.TS2 190).

Endereço para correspondência: Dra. Rugimar Marcovistz, Serviço de Controle de Qualidade, Instituto Butantan. Av. Brasil 1500, Butantan 05503-900, São Paulo, Brasil. Recebido para publicação em 01/09/95.
}

simples substituição de um aminoácido na posição 333 (Arg $\rightarrow$ Ile ou Gln) era essencial para a integridade de um determinante antigênico e responsável pela capacidade do vírus de produzir infeção não letal em camundongos. Posteriormente, Tuffereau e $\mathrm{col}^{2+}$ confirmaram que a substituição da arginina, na posição 333 , na molécula da glicoproteina de variantes avirulentas derivadas dos virus CVS e ERA, era fundamental para a avirulência dessas cepas.

Vários autores tem utilizado essas variantes, como uma ferramenta no estudo das características biológicas envolvidas na neurovirulência do vírus rábico ${ }^{718}$. Recentemente, Jackson $^{17}$ demonstrou que os vírus CVS e sua variante avirulenta RV194-2 disseminam-se igualmente no SNC de camundongos, entretanto, o CVS era capaz de infectar um número maior de neurônios do que o RV194-2.

Nosso trabalho teve como objetivo estudar a imunogênicidade do vírus RV194-2 em camundongos $\mathrm{BALB} / \mathrm{C}$ através da indução de interferon, da produção de anticorpos neutralizantes anti-rábicos e da proteção destes animais contra a cepa parental virulenta (CVS) usada como desafio.

\section{MATERIAIS E MÉTODOS}

Animais. Utilizamos camundongos BALB/c (idade de 6 semanas), fornecidos pelo Biotério Central da Fundação Oswaldo Cruz. 
Marcovistz R, Leal EC, Matos DCS, Araújo HP, Tsiang H. Imunogenicidade da cepa avirulenta RV194-2 do virus rábico em camundongos. Retista da Sociedade Brasileira de Medicina Tropical 29:579-583, nov-dez, 1996.

Células. As linhagens de células empregadas foram: L-929 (células epiteliais murinas), BHK21 (baby hamster kidney) e CER (chick embryo-related), cultivadas em meio mínimo de Eagle (MEM) suplementado com 10\% de soro fetal bovino (SFB).

Virus. Foram utilizadas duas cepas de vírus rábico: a cepa de vírus fixo, CVS, adaptada em camundongos e em células BHK21 e sua variante, avirulenta RV194-2, adaptada em células BHK21. As amostras originais destas cepas foram fornecidas pelo Serviço de raiva do Instituto Pasteur de Paris, França.

A cepa de vírus da encefalomiocardite murina (EMC) adaptada em células L929 foi fornecida pela Dra. Claire Kubelka (Dept ${ }^{\circ}$ de Virologia, Instituto Oswaldo Cruz).

Dosagem de anticorpos anti-rábicos. Os camundongos foram sangrados através de punção no plexo retroorbital, as amostras de sangue foram colocadas em tubos contendo heparina $(100 \mathrm{U} / \mathrm{ml})$ e o plasma separado por centrifugação. O método de inibição do foco de fluorescência, em cultura de células BHK21, foi utilizado para a dosagem de anticorpos anti-rábicos ${ }^{23}$.

Diluiçôes seriadas do plasma (1:2 a 1:1024) foram feitas em microplacas de 96 orifícios. A cada $25 \mu 1$ das diluições do plasma foi adicionado igual volume de uma suspensão de vírus CVS (adaptado em células BHK21 e previamente titulado) e 80ul de diluente (MEM com 5\% de SFB). Após incubação de 1 hora a $36^{\circ} \mathrm{C}$, em ambiente de $\mathrm{CO} 2(5 \%), 50 \mu 1$ de uma suspensão de células BHK21 $\left(10^{\circ} \mathrm{cel} / \mathrm{ml}\right)$ foram adicionados. Um volume de $10 \mu \mathrm{l}$ da mistura plasma, vírus e células foi transferido para placa de Terasaki. Após incubação a $36^{\circ} \mathrm{C}$ durante 24 horas, as células foram lavadas com solução salina tamponada (PBS contendo $\mathrm{Ca}++$ e $\mathrm{Mg}++)$ e fixadas em acetona (80\%) durante $1 / 2$ hora a $4^{\circ} \mathrm{C}$. Em seguida, o conjugado antinucleocapsídeo rábico ( $5 \mu \mathrm{l} /$ orifício), marcado $\mathrm{com}$ isotiocianato de fluoresceína (FITC) (Dignostic Pasteur, França), foi adicionado e após incubação por 30 minutos a $37^{\circ} \mathrm{C}$ e as células foram lavadas duas vezes com PBS. As placas secas foram examinadas ao microscópio de fluorescência.

Em paralelo, foi também titulado um soro de referência contendo $350 \mathrm{UI}$, fornecido pelo Instituto Nacional de Controle de Qualidade em Saúde da Fundação Oswaldo Cruz (INCQS-FIOCRUZ). Os títulos de anticorpos, expressos em unidades internacionais, foram determinados a partir do inverso das diluiçôes de plasmas capazes de inibir 50\% da replicação viral nas células BHK.

Extrato cerebral. Cérebros congelados foram macerados e homogeneizados em $2 \mathrm{ml}$ de uma solução tampão hipotônica, contendo $10 \mathrm{mM}$ de HEPES (pH 7,6), 10mM $\mathrm{de} \mathrm{KCl}, 2 \mathrm{mM}$ de $\mathrm{Mg}(\mathrm{OAC}) 2,7 \mathrm{mM}$ de 2 - $\beta$-mercaptoetanol e aprotinina a $100 \mathrm{U} / \mathrm{ml}$. Estes homogenatos foram deixados por 15 minutos a $4^{\circ} \mathrm{C}$ antes da adição de NP40 na concentração final de $0,5 \%$. Cada suspensão foi, então, sonicada por 10 segundos e centrifugada a $1500 \mathrm{~g}$ por 20 minutos ${ }^{13}$. Os extratos dos cérebros foram guardados a $-70^{\circ} \mathrm{C}$ para posterior avaliação da atividade da 2-5A sintetase.

Atividade de 2-5A sintetase. Os extratos de cérebro (200ul) foram colocados para reagir com 4001 de uma solução tampão hipotônica, contendo 20mM de HEPES ( $\mathrm{pH} 7,6$ ), $50 \mathrm{mM}$ de $\mathrm{KCl}, 25 \mathrm{mM}$ de $\mathrm{Mg}(\mathrm{OAC}) 2,7 \mathrm{mM}$ de 2-B-mercaptoetanol, $5 \mathrm{mM}$ de ATP, $10 \mathrm{mM}$ de fostato de creatinina, $0,16 \mathrm{mg} / \mathrm{ml}$ de creatina kinase, $0,1 \mathrm{mg} / \mathrm{ml}$ de poly(I).poly(C) e $20 \mu l$ de 3H-ATP $(0,1 \mathrm{mCi} / \mathrm{ml})$ (Amershan, Inglaterra). A mistura foi incubada a $30^{\circ} \mathrm{C}$ por 90 minutos e em seguida por 5 minutos a $80 / 90^{\circ} \mathrm{C}$. As moléculas de $2-5 \mathrm{~A}$ resultantes da ativação da 2-5A sintetase, foram purificadas por cromatografia em colunas de DEA-celulose e as amostras colocadas em frascos contendo líquido de cintilação. A contagem em cpm foi feita em analisador (Beta) de líquido de cintilação (PACKARD, Modelo: 1600 TRICARB) e a taxa de 2-5A sintetase foi expressa em nmol de AMP, incorporado na molécula de 2-5A por mg de proteína por 60 minutos.

Titulação de interferon. A atividade interferogênica no plasma e no cérebro (extrato cerebral sem NP40 e 2-ß3-mercaptoetanol) foi medida pela inibição do efeito citopático do vírus EMC sobre as células L-929 ${ }^{13}$

Microplacas de 96 orifícios, contendo diluições seriadas (1:2 a 1:1024) do plasma ou extrato cerebral foram expostas à luz ultra violeta, por 30 minutos. Em seguida, a cada diluição foi adicionado igual volume de uma suspensão de células L-929 $\quad\left(5,0 \times 10^{4}\right.$ cél/orifício) e as microplacas incubadas por 24 horas a $37^{\circ} \mathrm{C}$ em ambiente de CO2 (5\%). Após esse período, as células foram infectadas com 
Marcovistz R, Leal EC, Matos DCS, Araujo HP, Tsiang H. Imunogenicidade da cepa avirulenta RV194-2 do virus rábico em camundongos. Revista da Sociedade Brasileira de Medicina Tropical 29:579-583, nov-dez, 1996.

100 TCID50 do vírus EMC e reincubadas a $37^{\circ} \mathrm{C}$ em ambiente de $\mathrm{CO} 2(5 \%)$ por mais 24 horas.

O título do interferon foi dado pelo inverso da diluição das amostras testadas que apresentaram 50\% de efeito citopático causado pelo EMC.

Dosagem de proteinas. As proteínas dos extratos de cérebros foram dosadas com base na diferença de absorbância a 235 e $280 \mathrm{~nm}^{28}$.

Efeito protetor. Três grupos de 24 camundongos $\mathrm{BALB} / \mathrm{c}$ foram inoculados $\mathrm{com}$ $50 \mu l$ de uma suspensão do vírus RV194-2, por via intracerebral, nas concentrações de 100 , $1.000,10.000$ PFU. Um outro grupo também com 24 camundongos, foi inoculado com PBS

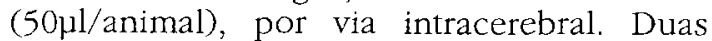
semanas após a inoculação, cada um dos grupos citados foi subdividido em dois grupos de 12 animais e desafiados, intracerebralmente, com a cepa CVS nas concentrações de 30 e 100 DL50, respectivamente. Os animais foram observados, quanto o aparecimento de sintomas da raiva, durante 30 dias após o desafio

\section{RESULTADOS}

Titulo de anticorpos anti-räbicos, indução de interferon e atividade da 2-5 A sintetase. A Tabela 1 mostra os resultados do título de anticorpos neutralizantes anti-rábicos, da presença de interferon no plasma e no cérebro, assim como, a atividade da $2-5^{\circ} \mathrm{A}$ sintetase no cérebro de camundongos inoculados com o virus RV194-2.

Tabela 1 - Titulo de anticorpos anti-räbicos, induçāo de interferon $e$ atividade da 2-5A sintetase no plasma e no cérebro de camundongos inoculados com vínus R $194-2$

\begin{tabular}{|c|c|c|c|c|}
\hline \multirow{3}{*}{$\begin{array}{l}\text { Dias } \\
\text { após } \\
\text { inoculaço }\end{array}$} & \multicolumn{2}{|c|}{ Plasilla } & \multicolumn{2}{|c|}{ Cérebro } \\
\hline & $\mathrm{ACN}$ & IFN & IFN Uimg & $2-5 A$ \\
\hline & $\mathrm{UV} / \mathrm{ml}$ & Uiml & de pin & nrnol/mg/h \\
\hline C & 0 & $\leq 40$ & $\leq 40$ & 0.30 \\
\hline 2 & 0.67 & 2560 & 2560 & 1,10 \\
\hline 4 & 2,67 & 2560 & $\geq 5120$ & 2.00 \\
\hline 8 & 68.13 & 1280 & 640 & 1.15 \\
\hline 12 & 204,00 & 320 & 320 & 1.00 \\
\hline 16 & 204,00 & $\leq 40$ & $\leq 40$ & 0 \\
\hline
\end{tabular}

Um grupo de 15 camundongos $\mathrm{BALB} / \mathrm{c}$ foi inoculado com o vírus RV194-2 por via intracerebral (100 PFUianimal). Cada resultado representa a média aritmética de três animais: AcN = anticorpos neutralizantes; IFN = interferon; $\mathrm{C}=$ indica os valores obtidos a partir de animais inoculados somente com PBS (controle).

Os anticorpos neutralizantes circulantes foram detectados a partir do $2^{\circ}$ dia após a inoculação do vírus e o título aumentou progressivamente até o $12^{\circ}$ dia, mantendo-se a seguir constante até o dia 16, quando o experimento foi encerrado.
A presença de interferon no plasma e no cérebro aumentou a partir do $2^{\circ}$ dia, decrescendo a partir do $8^{\circ}$ dia.

A indução da 2-5 A sintetase ocorreu em paralelo à produção de interferon no cérebro, mostrando um pico máximo de sua atividade no $4^{\circ}$ dia após a inoculação do vírus, com uma queda gradativa a partir do dia 8.

Efeito protetor. A Tabela 2 mostra o efeito do vírus rábico RV194-2 na indução da resistência de camundongos $\mathrm{BALB} / \mathrm{c}$ quando desafiados com a cepa CVS.

Tabela 2 - Efeito protetor do virus RV194-2 em camundongos $B A L B / C$.

\begin{tabular}{ccc}
\hline $\begin{array}{c}\text { Concentração } \\
\text { do virus }\end{array}$ & Taxa de sobrevivência (\%) \\
\cline { 2 - 3 } RV194-2 & Virus desafio (CVS) \\
\hline 0 & 30 DL50 & 100 DL50 \\
100 & $2 / 12(16.7)$ & $0 / 12(0)$ \\
1.000 & $12 / 12(100)$ & $12 / 12(100)$ \\
10.000 & $12 / 12(100)$ & $12 / 12(100)$ \\
\hline
\end{tabular}

Três grupos de 24 camundongos $\mathrm{BALB} / \mathrm{c}$ foram inoculados com $50 \mu \mathrm{g}$ de uma suspensão do víns RV194-2 por via intracerebral nas $50 \mu g$ de uma suspensão do vínus RV194-2 por via intracerebral nas
concentraçoes de 100. 1.000. 10.000 PFU. Duas semanas após a concentraçóes de 100 . 1.000. 10.000 PFU. Duas semanas após a
inoculaço. cada um dos três grupos foi subdividido em dois inoculação. cada um dos três grupos foi subdividido em dois
grupos de 12 animais e desafiados intracerebralmente com a cepa grupos de 12 animais e desafiados intracerebralmente com a cepa animais foram observados durante 30 dias após o desafio. $0=$ Representa o grupo de animais inoculados com PBS e desafiados com o vírus CVS.

Os três grupos de camundongos inoculados com diferentes concentraçôes $(100,1.000 \mathrm{e}$ $10.000 \mathrm{PFU}$ ) de virus foram $100 \%$ protegidos quando desafiados com 30 e 100 DL50 de vírus CVS por via intracerebral.

O grupo de animais controle inoculados somente com 30 e 100 DL50 de vírus CVS (desafio) tiveram uma mortalidade de 83,7 e $100 \%$, respectivamente.

\section{DISCUSSÃO}

Os resultados obtidos neste estudo demonstraram que os camundongos $\mathrm{BALB} / \mathrm{c}$, inoculados por via intracerebral com o vírus avirulento RV194-2, apresentaram altos títulos de interferon e de anticorpos anti-rábicos neutralizantes, além da proteção contra o vírus parental virulento, CVS.

A produção de interferon é uma das primeiras defesas do organismo consequente de uma infecção viral ${ }^{1111 \text { 1521 }} \mathrm{e}$ a importância de seu papel, em diferentes modelos animais infectados com vírus rábico tem sido bem documentada ${ }^{19}$. Em concordância com esses dados, também encontramos altas taxas de interferon no plasma e no cérebro dos animais 
Marcovistz $R$, Leal EC, Matos DCS, Araüjo HP, Tsiang H. Imunogenicidade da cepa avirulenta RV194-2 do vínus rábico em camundongos. Revista da Sociedade Brasileira de Medicina Tropical 29:579-583, nov-dez, 1996.

inoculados com o vírus RV194-2. Além disso, a 2-5A sintetase, um dos marcadores da presença e ação do interferon em um organismo e em culturas de tecidos ${ }^{13}$, aumentou sua taxa paralelamente à do interferon produzido no cérebro dos animais inoculados com o vírus RV194-2. Esses resultados evidenciam que o interferon produzido nos animais infectados com o virus RV194-2 é tão ativo quanto o produzido em resposta à infecções por cepas virulentas ${ }^{20}$.

Estudo imunohistoquímico realizado por Dietzschold e colp mostrou que o vírus CVS disseminou mais rápido do córtex para o cerebelo e infectou mais neurônios do que o vírus RV194-2, no SNC dos animais. Posteriormente, resultados semelhantes mostrando reduzida capacidade da replicação do vírus RV194-2 no SNC dos animais. Posteriormente, resulatdos semelhantes mostrando a capacidade da replicação do vírus RV194-2 no SNC de camundongos, quando comparada com a cepa CVS, também foram observados por outros pesquisadores ${ }^{7} 161718$. Essa menor eficiência da disseminação do vírus RV194 2 no SNC, provavelmente, permite um maior tempo de exposição das partículas virais ou antígenos virais às células do sistema imune, e em parte, explicaria os altos títulos de anticorpos anti-rábicos encontrados no plasma dos camundongos $\mathrm{BALB} / \mathrm{C}$ inoculados com o vírus RV194-2.

Por outro lado, o vírus RV194-2 mostrou-se altamente imunogênico, induzindo proteção aos camundongos quando desafiados com o vírus CVS. Esta proteção, certamente, foi devida aos altos níveis de anticorpos e de interferon encontrados nos animais inoculados com o vírus RV194-2. É importante notar que vários autores têm demonstrado a importância dos interferons como imumoduladores na evolução da infecção rábica ${ }^{21}{ }^{21}$, e na eficácia de vacinas anti-rábicas ${ }^{12}$.

Os resultados aqui apresentados sugerem que a cepa RV194-2 pode ser um excelente instrumento para os estudos sobre a interaçâo dos sistemas nervoso e imunitário, e talvez uma promissora candidata para estudos de novas vacinas.

\section{SUMMARY}

RV194-2 rabies virus, an avirulent mutant of CVS strain, induces an inapparent infection limited to the central nervous system (CNS) in adult mice inoculated intracerebrally. This fact suggest that immune response of the bost is able to eliminate the virus in CNS. For this reason, we have studied the induction of interferon and the bumoral immune responses in $B A L B / C$ mice after RV194-2 inoculation. These mice presented bigh levels of interferon in the plasma and in the brain, with elevated levels of neutralizing antirabies antibodies. The 2-5A synthetase, an enzyme marker of interferon action, was analyzed in the brain of inoculated animals. Its enbancement in parallel to the interferon production in the brain, showed biochemical evidence that this interferon is active. Forty five days after RV194-2 virus inoculation, mice were protected against a challenge with the CVS virulent strain. The results presented berein show that RV194-2 strain bas a bigh level of immunogenicity.

Key-words: Rabies virus. Interferon. Immunogenicity.

\section{REFERÊNCIAS BIBLIOGRÁFICAS}

1. Atanasiu P. Role de l' interferferferon dans l' immunité antirabique. Compendium of Immunology and Microbiology of Infectious Diseases. 5: 123-127, 1982.

2. Baer GM, Yager PA. A mouse model for rabies post-exposure rabies prophylaxis. Comparative efficacy of vaccine and the antiserum administration.Journal of General Virology 36:51$57,1977$.

3. Buffet-Janvresse C, Magared H, Robert N, Hovanessian AG. Assay and levels of 2-5A synthetase in lymphocytes of patients with viral, bacterial and auto immune diseases. Annalles de Immunologie (Institut Pasteur) 134D:247-258, 1983.

4. Coulon P, Derbin C, Kucera P La Fay I, Prehaud C, Flamand A. Invasion of the peripheral nervous system of adult mice by the CVS strain of rabies virus and avirulent derivative AQV01. Journal of Virolology 63:3550-3554, 1989.

5. Coulon $P$, Rollin $P$, Aubert $M$, Flamand $A$. Moleculare basis of rabies virulence. I. Selection of avirulent mutants of the CVS strain of rabies virus with anti-G monoclonal antibodies. Journal of General Virology 61:97-100, 1982a.

6. Coulon P, Rollin P, Blancou J, Flamand A.Avirulent mutant of CVS strain of rabies virus. Compendium of Immunology and Microbiology Infectious Disease 5:117-122, 1982b. 
Marcolistz R, Leal EC, Matos DCS, Aranjo HP, Tsiang H. Imunogenicidade da cepa avirulenta RV194-2 do vírus rábico em camundongos. Revista da Sociedade Brasileira de Medicina Tropical 29:579-583, nov-dez, 1996.

7. Coulon P, Rollin P., Flamand A. Molecular basis of rabies virulence. II. Indentification of a site on the CVS glycoprotein associated with virulence. Journal of General Virology 64:693-696,1983.

8. Dietzschold B, Wiktor JT, Trojanowski JQ, Macfarlan RI Wunner WH, Torres-Angel MJ Koprowski H. Differences in cell-to-cell spread of pathogenic and apathogenic rabies virus in tivo an in vitro. Journal of Virology 56:12-18, 1985.

9. Dietzschold B, Wunner WH, Wiktor TJ, Lopes AD, Lafon M, Smith CL, Koprowski H. Characterization of an antigenic determinant of glycoprotein that correlates with pathogenicity of rabies virus. Proccedings of National Academy of Sciences 80:70-74, 1983.

10. Famand A, Wiktor TJ, Koprowisk H. Use of hybridoma monoclonal antibodies in the detection of antigenic differences between rabies and rabies related virus protein. II. The glicoprotein. Journal of General Virology 48:105$109,1980$.

11. Galabru J, Robert N, Buffet-Janvresse C, Rivière YL, Hovanessian AG. Continuous production of interferon in normal mice: Effect of anti interferon globulin, sex, age, strain and inviromment on the levels of 2-5A synthetase and pG7k kinase. Journal of General Virology 66:711$718,1985$.

12. Hillman MR. Interferon induction and utilization. Journal of Cell Physiology 71:43-60, 1968.

13. Hovanessian AG, Rivière Y. Interferon-mediated induction of 2-5A synthetase and protein in the liver and spleen of mice infected with New Castle disease virus as injected with poly (I). poly (C). Annalles de Virologie (Institut Pasteur) 131E:501-516, 1980.

14. Isaacs A, Burke DC. Viral interference and interferon 15:185-188, 1959.

15. Isaacs A, Lindenmann J. Virus interference. I. the interferon. II. Some properties of interferon. Proccedings of Royal Society of Medicine 147B:258-267, 1957.

16. Jackson AC. Biological basis of rabies virus neurovirulence in mice: Comparative pathogenesis study using the immunoperoxidase technique. Journal of Virology 65:537-540, 1991.

17. Jackson AC, Reimer DL. Pathogenesis of experimental rabies in mice: an immunohistochemical study.Acta Neuropathologica 78:159-165, 1989.
18. Kucera $\mathrm{P}$, Dolivo $\mathrm{M}$, Coulon $\mathrm{P}$, Flamand A. Pathways of the early propagation of virulent and avirulent rabies strain from the eye to the brain. Journal of Virology 55:158-162, 1985.

19. Lodmell DL, Wildbrank DL, Ewalt LC. Interferon induced within the central nervous system during infection is in consequencial as a mechanism responsible for murine resistence to street rabies virus. Journal of General Virology 70:473-478, 1989.

20. Marcovistz R, Galabru J,Tsiang H, Hovanessian AG, Neutralization of interferon produced early during rabies virus infection in mice. Journal of General Virology 67:387-390, 1986.

21. Marcovistz $R$, Germano PML, Tsiang $H$, Hovanessian AG. The effect of interferon treatment in rabies prophylaxis in immunocompetent, immunosuppressed and immunodeficient mice. Journal of Interferon Research 7:17-27, 1987.

22. Marcovistz $R$, Tsiang $H$, Hovanessian AG. Prodoction and action of interferon in mice infected with rabies virus.Annalles de Virologie (Inst Pasteur) 135E: 19-33, 1984.

23. Reagan KJ, Wunner WH, Wiktor TJ, Koprowski H. Anti-idiotipic antibodies induce neutralizing antibodies to rabies virus glycoprotein. Journal of Virology 48:660-666, 1983.

24. Tuffereau C, Lebois H, Benejean J, Coulon P, Lafay F, Flamand A.Arginine or lysine in position 333 of ERA and CVS glycoprotein is necessary for rabies virulence in adult mice. Virology 172:206-212, 1989.

25. Wiktor TJ, Clark HF. Comparation of rabies virus strains by means of plaque reduction test. Annalles de Microbiologie (Institut Pasteur) 124A:283-287, 1973.

26. Wiktor TJ, Koprowski H. Monoclonal antibody against rabies virus produced by somatic cell hybridization: Detection of antigenic variants. Proccedings of National Academy of Sciences (USA). 75:3938-3942, 1978.

27. Wiktor TJ, Koprowski $H$. Antigenic variants of rabies virus. Journal of Experimental Medicine 152:99-112, 1980.

28. Witaker RJ, Granun PE. An absolute methods for protein determination based on difference in absorbance at 235 and $280 \mathrm{~nm}$. Annals of Biochemistry 109:156-159, 1980. 